\title{
Downregulation of NMI promotes tumor growth and predicts poor prognosis in human lung adenocarcinomas
}

Jingshu Wang ${ }^{1,5+}$, Kun Zou ${ }^{3 \dagger}$, Xu Feng $^{4 \dagger}$, Miao Chen ${ }^{1}$, Cong Li ${ }^{1}$, Ranran Tang ${ }^{4}$, Yang Xuan ${ }^{4}$, Meihua Luo ${ }^{2}$, Wangbing Chen ${ }^{6}$, Huijuan Qiu', Ge Qin ${ }^{1}$, Yixin Li ${ }^{1}$, Changlin Zhang ${ }^{1}$, Binyi Xiao ${ }^{1}$, Lan Kang ${ }^{4}$, Tiebang Kang ${ }^{1}$, Wenlin Huang ${ }^{1,7}$, Xinfa $\mathrm{Yu}^{2^{*}}$, Xiaojun $\mathrm{Wu}^{1 *}$ and Wuguo Deng ${ }^{1,7^{*}}$

\begin{abstract}
Background: N-myc (and STAT) interactor (NMI) plays vital roles in tumor growth, progression, and metastasis. In this study, we identified NMI as a potential tumor suppressor in lung cancer and explored its molecular mechanism involved in lung cancer progression.

Methods: Human lung cancer cell lines and a mouse xenograft model was used to study the effect of NMI on tumor growth. The expression of NMI, COX-2 and relevant signaling proteins were examined by Western blot. Tissue microarray immunohistochemical analysis was performed to assess the correlation between NMI and COX-2 expression in lung cancer patients.

Results: NMI was highly expressed in normal lung cells and tissues, but lowly expressed in lung cancer cells and tissues. Overexpression of NMl induced apoptosis, suppressed lung cancer cell growth and migration, which were mediated by up-regulation of the cleaved caspase-3/9 and down-regulation of phosphorylated PI3K/AKT, MMP2/MMP9, $\beta$-cadherin, and COX-2/PGE2. In contrast, knockdown of NMI promoted lung cancer cell colony formation and migration, which were correlated with the increased expression of phosphorylated PI3K/AKT, MMP2/MMP9, $\beta$-cadherin and COX-2/PGE2. Further study showed that NMI suppressed COX-2 expression through inhibition of the p50/p65 NF-kB acetylation mediated by p300. The xenograft lung cancer mouse models also confirmed the NMI-mediated suppression of tumor growth by inhibiting COX-2 signaling. Moreover, tissue microarray immunohistochemical analysis of lung adenocarcinomas also demonstrated a negative correlation between NMI and COX-2 expression. Kaplan-Meier analysis indicated that the patients with high level of NMI had a significantly better prognosis.
\end{abstract}

Conclusions: Our study showed that NMI suppressed tumor growth by inhibiting PI3K/AKT, MMP2/MMP9, COX2/PGE2 signaling pathways and p300-mediated NF-KB acetylation, and predicted a favorable prognosis in human lung adenocarcinomas, suggesting that NMI was a potential tumor suppressor in lung cancer.

Keywords: NMI, COX-2, NF-KB, p300, Lung cancer

\footnotetext{
*Correspondence: yuxfa@126.com; wuxj@sysucc.org.cn;

dengwg@sysucc.org.cn

${ }^{\dagger}$ Equal contributors

${ }^{2}$ Shunde Hospital, Southern Medical University, Foshan, China

${ }^{1}$ Sun Yat-sen University Cancer Center; State Key Laboratory of Oncology in

South China; Collaborative Innovation Center of Cancer Medicine,

Guangzhou, China

Full list of author information is available at the end of the article
} 


\section{Background}

Lung cancer is becoming the leading cause of cancerrelated deaths worldwide $[1,2]$. It is also the most common incident cancer and the leading cause of cancer death in China [3]. Non-small-cell lung cancer (NSCLC) accounts for more than $85 \%$ of lung cancer [4], while adenocarcinoma (AC) accounts for approximately $60 \%$ of all NSCLC and is the most frequently diagnosed subtype of NSCLC [5]. People with NSCLC can be treated with surgery, chemotherapy, radiation therapy, targeted therapy, or a combination of these. Although target therapy against epidermal growth factor receptor (EGFR) mutations and echinoderm microtubule-associated protein-like 4-anaplastic lymphoma kinase (EML4-ALK) rearrangements improved the prognosis in the last decade [6], mutations in EGFR are only present in $10-26 \%$ of NSCLC [7], and EML4-ALK rearrangements are only found in 4$5 \%$ of NSCLC [8]. Most patients are not associated with these mutations, and patients with advanced NSCLC are resistant to chemotherapy and radiotherapy. Therefore, improvements in lung cancer diagnostics and new treatments are urgently needed.

$\mathrm{N}$-myc (and STAT) interactor (NMI) is a protein that interacts with NMYC and CMYC (members of the oncogene Myc family), and other transcription factors containing a Zip, HLH, or HLH-Zip motif [9]. The NMI protein interacts with all STATs except STAT2 and augments STAT-mediated transcription in response to cytokines IL2 and IFN- $\gamma$ [9]. NMI is an IFN- $\gamma$ inducible gene product that interacts with several key molecules in carcinogenesis such as SOX10 and TIP60 [10-14]. NMI may augment coactivator protein recruitment to some specific transcription factors, enhance the association of p300/CBP coactivator proteins with STAT1 and STAT5, and together with p300/CBP, augment IL2 and IFN- $\gamma$ dependent transcription [9]. Previous studies demonstrated that NMI expression decreased in the progression of advanced invasive breast cancers [15-17], and loss of NMI expression promoted epithelial-mesenchymal-transition (EMT) [15]. It was also shown that restoring NMI expression inhibited tumorigenic and metastatic cell lines from anchorage independent and invasion related growth, and retarded tumor xenograft growth by inhibiting the Wnt/ $\beta$-catenin signaling pathway and up-regulating Dkk1 [18]. In addition, NMI played a vital role in autophagy induction. Loss of NMI reduced the autophagy responsiveness and chemosensitivity of breast cancer cells [19]. Sun et al. identified NMI as an interactor of apoptin, a viral apoptosis inducing protein [20]. Nagel et al. discovered that the interaction between STAT5, NMI and N-myc repressed myocyte enhancing factor $2 \mathrm{c}$ and increased apoptosis in $\mathrm{T}$ cell acute lymphoblastic leukemia, suggesting that NMI might be involved in cancer cell specific apoptosis [21]. However, little is known about the function of NMI in lung cancer. In this study, we have found that NMI may promote apoptosis and inhibit cell growth and migration in lung cancer cells. Notably, we have shown that NMI regulates COX-2, an inducible enzyme that plays a vital role in carcinogenesis process.

COX-2 plays a key role in multiple pathophysiological processes including inflammation and carcinogenesis, as it influences apoptosis, angiogenesis, and invasion [22]. COX-2 is known to produce prostaglandin E2 (PGE2) that regulate tumor-associated angiogenesis, modulate the immune system, promote cell migration and invasion, and inhibit apoptosis, all of which promote cancer progression [23]. COX-2 is overexpressed in a wide range of human cancers, such as human cancers of colorectal [24, 25], breast [26], lung [27, 28], bladder [29-31], uterine cervix $[32,33]$, liver [34], pancreas [35, 36], prostate [37], skin [38], esophagus [39, 40] and stomach [41, 42]. COX-2 overexpression is positively related to poor survival [31, 43, 44], increased metastasis events, and invasive properties. In addition, COX-2 overexpression is associated with apoptosis resistance [45], and abnormal cell proliferation as a result of apoptotic cell death inhibition. In contrast, inhibition of COX-2 induces apoptosis signaling in various human cancers [46-48]. The COX-2 gene promoter contains an NF$\mathrm{\kappa B}$ response element as well as other cytokinedependent (i.e., IL6) response elements [49]. COX-2 expression is transcriptionally controlled by the binding of activators such as NF- $\mathrm{kB}$ and coactivators such as p300 to the corresponding sites of its promoter [50-53]. However, it is unclear whether COX-2 expression is regulated by NMI in human lung cancer cells.

In this study, we investigated the role of NMI in the regulation of cell proliferation, apoptosis, and migration in human lung cancers, and also explored its underlying molecular mechanisms involved in PI3K/ AKT, Erk/p38, MMP9/ $\beta$-cadherin, NF-кB/COX-2/ PGE2, and PARP/Bcl-2/Caspase3 signaling pathways. Tissue microarray and immunohistochemical analysis were also performed to assess the correlation between NMI and COX-2 expression. Moreover, we further identified the role of the transcriptional coactivator p300 in the NMI-mediated regulation of COX-2 expression and cell growth in lung cancer cells. Finally, we studied the clinical significance of the NMI/COX2 signaling pathways in lung adenocarcinoma patients using Kaplan-Meier and multivariate survival analyses. The results from our study not only revealed the novel role of NMI in regulating lung cancer growth, 
but also provided a possibility for the development of NMI as a new potential tumor suppressor.

\section{Methods}

\section{Cell lines and cell culture}

H1299, HLF (HLF-a) and HBE cells were cultured in Dulbecco's modified Eagle's medium (DMEM) supplemented with $10 \%$ fetal bovine serum (FBS). A549 and H460 cells were cultured in RPMI1640 medium supplemented with $10 \%$ FBS. The cells were grown at $37{ }^{\circ} \mathrm{C}$ in an atmosphere of $5 \% \mathrm{CO} 2$. All the cell lines were obtained from the American Type Culture Collection (ATCC, Manassas, VA).

\section{Plasmids}

The NMI overexpression plasmid pEZ-Lv203-NMI (Catalog No.: EX-K2261-Lv203) and its control vector pEXNEG-Lv203 (Catalog No.: EX-NEG-Lv203), NMI shRNA plasmid psi-LVRH1GP-NMI (Catalog No.: HSH022093LVRH1GP) and its control vector psi-LVRH1GP (Catalog No.: CSHCTR001-1-LVRH1GP) were obtained from GeneCopoeia (Rockville, MD). The target sequence of NMI shRNA1 is $5^{\prime}$-gagtgcagtcatcacgttt-3', and the target sequence of NMI shRNA2 is $5^{\prime}$-ctaggtcaacctcacatag-3'. A549 and H1299 cells were transfected with corresponding plasmids to overexpress or knock down NMI.

\section{Transfection}

The cells $\left(2 \times 10^{5} / \mathrm{ml}\right)$ seeded in 6-well plates overnight were mixed gently $4 \mu \mathrm{g}$ shRNA or plasmids and $10 \mu \mathrm{l}$ of Lipofectamine 3000 (Invitrogen, Carlsbad, CA) in $250 \mu \mathrm{l}$ opti-MEM (Gibco, Gaithersburg, MD) and incubated at $37{ }^{\circ} \mathrm{C}$ for $48 \mathrm{~h}$.

\section{Lysate preparation from tumor tissues}

Lung cancerous tumors and adjacent tissues were obtained from 20 lung adenocarcinoma patients who underwent surgery therapy at the First Affiliated Hospital of Dalian Medical University between 2014 and 2015. The surgery and the study had been approved by the medical ethics committee at the First Affiliated Hospital of Dalian Medical University, and the informed consents were obtained from patients in accordance with the Declaration of Helsinki and with institutional guidelines. The tissues $(100 \mathrm{mg})$ were washed with PBS to remove blood, transferred to liquid nitrogen immediately and homogenized thoroughly with RIPA buffer with protease inhibitor. After incubation on ice for $30 \mathrm{~min}$, these tissues were sonicated for 2 to $5 \mathrm{~min}$ at power of about $180 \mathrm{~W}$. The lysates were centrifuged at $12,000 \mathrm{~g}$ for $20 \mathrm{~min}$ at $4{ }^{\circ} \mathrm{C}$, and the supernatants were collected.

\section{Western blot}

Protein lysates $(40 \mu \mathrm{g})$ were separated by $4 \%$ to $12 \%$ SDS-PAGE, electrophoretically transferred to PVDF membranes, immunoblotted at $4{ }^{\circ} \mathrm{C}$ overnight with antibodies against NMI, p300 (Santa Cruz Biotechnology, Santa Cruz, CA), $\beta$-actin, COX-2, p-PI3K, PI3K p85 (Tyr458)/p55 (Tyr199), Akt, p-Akt (Ser473), p-PDK1, pGSK3 $\beta$, p110 $\beta$, P38, p-P38, ERK1/2, pPARP, pTyr202/ Y204-ERK1/2, cleaved caspase-3, cleaved caspase-9, MMP2, MMP9, E-cadherin, B-cadherin (all purchased from Cell Signaling Technology, Beverly, MA), Bcl2 (Proteintech, Wuhan, China), followed by incubation with HRP-conjugated second antibody, and finally detected by enhanced chemiluminescence.

\section{PGE2 assay}

Three days after transfection, cell culture media were collected. The amounts of PGE2 in the media were determined by Human Prostaglandin E2 (PGE2) ELISA Kit (Bluegene Biotech).

\section{Analysis of promoter activity}

The promoter of human COX-2 gene $(-891$ to +9$)$ was truncated to 6 different lengths. Each fragment was inserted into a luciferase reporter vector pGL3. Luciferase reporter assays were performed using the kit Dual-Luciferase ${ }^{\bullet}$ Reporter Assay System (Promega, Madison, WI).

\section{Cell viability assay}

Cells were seeded into 96 well plates $\left(4 \times 10^{3}\right.$ cells per well). Cell viability was measured by MTT assay $48 \mathrm{~h}$ after transfection.

\section{Apoptosis analysis}

Cells were transfected with NMI overexpression or shRNA plasmid. After $48 \mathrm{~h}$, cells were trypsinized, harvested, washed with PBS twice, and resuspended in Annexin V Binding Buffer at a concentration of 0.25$1.0 \times 10^{7}$ cells $/ \mathrm{ml} .100 \mu \mathrm{l}$ cell suspension was transferred to a $5 \mathrm{ml}$ test tube, and $5 \mu \mathrm{l}$ of APC Annexin V was added in, followed by the addition of $5 \mu \mathrm{l}$ 7-AAD Viability Staining solution, per instructions of the Annexin $\mathrm{V}$ APC/7AAD staining kit (Keygen biotech, Jiangsu, China). Cells were pipetted up and down and incubated for $15 \mathrm{~min}$ at room temperature in the dark. Finally, $400 \mu \mathrm{l}$ Annexin V Binding Buffer was added to each tube before the cells were analyze by flow cytometry (Beckman Coulter, Brea, CA). Apoptosis was measured in terms of the 7AAD-positive cells.

\section{Scratch assay}

Cells were seeded in 6-well plates $\left(4 \times 10^{5}\right.$ cells per well), and were grouped as (a) PBS control, (b) LacZ 
control, (c) NMI overexpression (d) control shRNA, (e) NMI shRNA1, (f) NMI shRNA2. 12 h after transfection, cells were scratched with sterile $200 \mu \mathrm{l}$ tips, and photographed at $0 \mathrm{~h}, 48 \mathrm{~h}$ and $72 \mathrm{~h}$.

\section{Confocal immunofluorescence}

Cells were incubated on chamber slides in 6-well plates with or without NMI shRNA transfection. The samples were fixed with $4 \%$ polyoxymethylene for $30 \mathrm{~min}$ at room temperature, permeabilized with PBST (PBS with $0.2 \%$ Triton X-100), blocked with bovine serum albumin (BSA) for $30 \mathrm{~min}$ and incubated with NMI and p300 antibodies (1:200 dilution) overnight at $4{ }^{\circ} \mathrm{C}$. After washed 3 times, cells were incubated with the fluorescein isothiocyanate and rhodamine conjugated secondary antibodies for $1 \mathrm{~h}$. The nuclei were counterstained with 40,6-diamidino-2phenylindole (DAPI). The images were taken by Olympus confocal laser scanning microscope.

\section{Immunoprecipitation (IP)}

Nuclear protein $(1 \mathrm{mg})$ was used for each IP. The proteins were pulled down with Protein A/G sepharose and then detected by Western blot analysis with specific antibodies.

\section{Animal study}

Female nude mice ( 4 to 5 weeks old) were maintained in SPF laboratory Animal Central. All animals' maintenance and procedures were carried in accordance with the National Institute of Health Guide for the Care and Use of Laboratory Animals, and passed through the training progress and approval by Animal Care and Ethics Committee of Sun Yat-sen University Cancer Center. Each nude mouse was injected with $2 \times 10^{5}$ human A549 cells suspended in $100 \mu \mathrm{l}$ PBS, subcutaneously near the axillary fossa. The mice were randomly divided into 5 groups (6 per group): (a) control plasmid (Ctrl); (b) NMI overexpression (NMI); (c) control plasmid + lipopolysaccharides (Ctrl + LPS); (d) NMI overexpression plasmid + LPS (NMI + LPS); (e) NMI shRNA + LPS (shRNA + LPS). As a transfection reagent, the complex of cholesterol-conjugated plasmid $(10 \mu \mathrm{g})$ suspended in $100 \mu \mathrm{l}$ saline were injected twice a week for 3 weeks. The dose of LPS for each mouse is $10 \mu \mathrm{g} / \mathrm{kg}$, and LPS was injected twice a week for 2 weeks. Tumors volumes and body weights were measured every day. Tumor volumes were calculated as $\mathrm{V}=1 / 2$ (width ${ }^{2} \times$ length). Mice were humanely sacrificed by euthanasia after treatment.

\section{Human tissue microarray}

The human tissue micro arrays were purchased from Outdo Biotech Company (Shanghai, China). 75 cases from 75 lung cancer patients in total were arranged into two tissue array blocks.

\section{Human tissue immunohistochemistry}

Slides were deparaffinized, rehydrated and then immersed in a target retrieval solution $(\mathrm{pH} 6)$ and boiled at medium baking temperature for three times with 10 min once in a microwave. After blocking the slides with 3\% BSA, the sections were incubated with primary antibodies against NMI (Santa Cruz Tech., dilution 1:100) and COX-2 (Epitomics, dilution 1:100), and then with HRP-labeled anti-rabbit IgG secondary antibody. The specimens were counter stained with hematoxylin. A negative control was obtained by replacing the primary antibody with a regular rabbit IgG. The target-positive cells were counted in 3-4 different fields and photographed using an Olympus microscope, and the immunoreactions were evaluated independently by two pathologists blinded to the clinicopathologic information to ensure proper tissue morphology. Antibody staining intensity was categorized: no staining as 0 , weak as 1 , moderate as 2 , and strong as 3. A five-scale system was used to categorize the percentage of cells strained: 0 (no positive cells), $1(<25 \%$ positive cells), 2 ( $25 \%-50 \%$ positive cells), 3 ( $50 \%-75 \%$ positive cells), and 4 ( $>75 \%$ positive cells). The score for each tissue was calculated by multiplying the intensity index with the percentage scale, and the range of this calculation was therefore $0-12$. The median value of NMI scores was employed to determine the cutoff. Tumors with NMI scores lower or equal to the median were designated as "low expression", whereas those with scores higher than the median were designated as "high expression".

\section{TCGA Data analysis}

The mRNA sequencing data of lung adenocarcinoma samples $(n=576)$ from The Cancer Genome Atlas (TCGA) were downloaded from UCSC XENA database, gene expression RNAseq (IlluminaHiseq pancan normalized) dataset. All samples were divided into three groups (i.e. high or $\mathrm{H}$, red in heat map; medium or $\mathrm{M}$, black in heat map; and low or L, green in heat map) based on raw gene expression values. NMI scores higher than $66.6 \%$ of the patients' NMI scores were designated as "high expression", between $66.6 \%$ and $33.3 \%$ of the patients' were "medium expression", and lower than $33.3 \%$ of the patients' were "low expression". All the samples were selected and used for analysis. The correlations of gene expression were accessed by Pearson correlation coefficient.

\section{Statistical analysis}

Student's t-tests were used to compare two independent groups of data. Chi-square tests were applied to analyze the correlation between NMI expression and clinicopathologic features of lung adenocarcinomas patients. Survival curves were constructed using the KaplanMeier method and were compared using the log rank 
test. Multivariate Cox proportional hazards analyses used "Enter" modeling to generate models predictive of outcome. Spearman correlation was used to explore the relationship between the abundance of NMI and COX-2 . All calculations were performed with IBM SPSS 22 for Windows (SPSS, New York, NY, USA).

The results were presented as the mean \pm SD of three independent tests. ${ }^{*} P<0.05,{ }^{* *} P<0.01$, significant difference between the treatment and control groups.

\section{Results}

The expression of NMI was decreased in lung cancer cells and tumor tissues

To analyze the expression of NMI in human lung cancer, we first detected the protein level of NMI in human lung fibroblasts cell line HLF, immortalized human epithelial HPV-16 E6/E7 transformed cell line HBE, and human lung cancer cell lines H322, H1299, H460 and A549 by Western blot and quantitative analysis. The result showed that NMI was expressed in all the tested cell lines, but lung cancer cells (H322, H1299, H460 and A549) had lower expression of NMI when compared with HLF cells (Fig. 1a). We next examined the expression of NMI and COX-2 in tumor tissues and their adjacent tissues from 20 lung adenocarcinoma patients using immunohistochemical and quantitative analysis. We found that 16 out of the 20 tumor samples $(\mathrm{T})$ had lower expression of NMI and higher expression of COX2 compared to their adjacent normal tissue samples $(\mathrm{N})$. Five representative tumor $(\mathrm{T}) /$ normal $(\mathrm{N})$ pairs were shown in Fig. 1b. This result was consistent with the observation in lung cancer cell lines H460 and A549 compared to normal cell line HLF (Fig. 1a). These data indicated that the expression of NMI may be negatively correlated with COX-2 levels in lung adenocarcinoma cases. We further investigated the expression of NMI in lung cancer tissues by immunohistochemistry assay. 75 tumor tissues and their adjacent normal tissues were tested, and NMI expression was observed in the nucleus and the cytoplasm of the cells in both tumor tissues and normal tissues. Among the 75 tumor tissues, 15 showed strong NMI expression, 33 moderate, 22 weak, and 5 negative. In contrast, among the 75 adjacent normal tissues, 29 showed strong expression of NMI protein, 35 moderate, 8 weak, and 3 negative (Fig. 1c). The representative images for NMI expression in lung cancer tissues and normal tissues were shown in Fig. 1d. These results suggested that NMI had lower expression in lung cancer cells and tissues.

NMI inhibited proliferation and induced apoptosis of lung cancer cells

The effect of NMI on lung adenocarcinoma cell proliferation was evaluated in lung cancer cell lines A549 and
H460 by colony formation and quantitative analyses. NMI overexpression significantly inhibited the proliferation of both A549 and H460 cells. In contrast, knockdown of NMI remarkably promoted the proliferation and increased the clone volume of A549 and H460 cells (Fig. 2a). These results indicated that NMI played an important role in regulating lung adenocarcinoma cell proliferation. Next, the effect of NMI on apoptosis was investigated by Annexin V APC-7AAD staining-based FACS analysis. Overexpression of NMI significantly induced apoptosis in both A549 and H460 cells (Fig. 2b). We then examined the effect of NMI on the expression and activation of four key proteins in the apoptosis signaling pathway: Bcl-2, caspase-3, caspase- 9 , and PARP in A549 and H460 cells. Overexpression of NMI repressed the anti-apoptotic protein $\mathrm{Bcl}-2$, and activated caspase-3, caspase- 9 and PARP, which was indicated by marked increases in cleaved caspase-3, cleaved caspase- 9 and phosphorylated PARP (Fig. 2c). Thus, these results indicated that NMI might control several aspects of apoptosis signaling. To further identify the potential molecular mechanisms by which NMI inhibited lung cancer cell growth, we analyzed the expression of a series of pro-survival proteins possibly affected by NMI by Western blot and quantitative analysis. The results showed that NMI knockdown in A549 and H460 cells dramatically enhanced the phosphorylation of PI3K, AKT, PDK1, GSK-3 $\beta$ and $\mathrm{p} 110 \beta$ proteins, but did not change the expression of total PI3K, AKT proteins themselves (Fig. 2d). On the contrary, overexpression of NMI in A549 and H460 cells significantly inhibited the phosphorylation of PI3K, AKT, PDK1, GSK-3 $\beta$, and p110 $\beta$ proteins, without changing the levels of total PI3K and AKT (Fig. 2e). We also observed the up-regulation of the phosphorylation of ERK and p38 in the MAPK signaling pathway upon NMI silencing (Fig. 2d). These data suggested the possible involvement of PI3K/AKT/MAPK signaling pathways in NMI-mediated lung cancer cell growth inhibition.

\section{NMI inhibited lung cancer cell migration}

We further investigated whether the NMI-mediated inhibition in lung cancer cells was associated with the impeded cell migration ability. We examined the effect of NMI overexpression or knockdown on the migration of A549 and H460 cells by scratch assay. The gap between cell layers made by a scratch was much wider in the NMI-overexpressed cells, but it was much narrower in the NMI-knockdown cells (Fig. 3a, b). Additionally, the expression of MMP2 and MMP9, two key molecules involved in cell migration, was significantly increased in NMI-knockdown cells. Meanwhile, the expression of Ecadherin, which plays a critical role in cell adhesion, was markedly down-regulated, whereas the expression of 


\section{a}

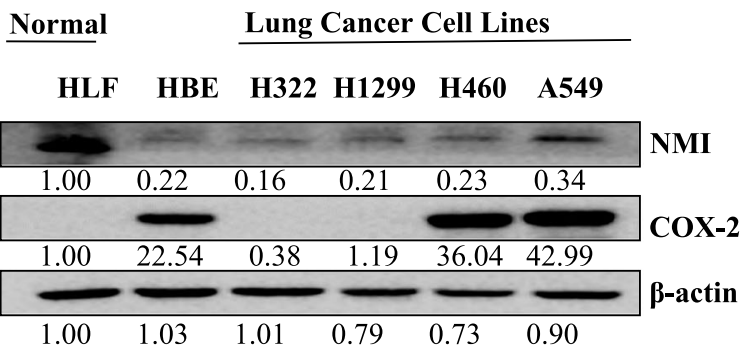

b

$\frac{1}{N T} \frac{2}{N T} \frac{3}{N T} \frac{4}{N T} \frac{5}{N T}$

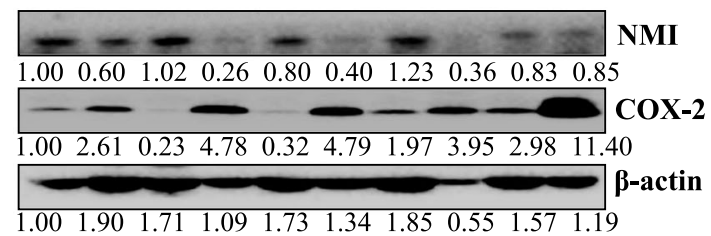

C

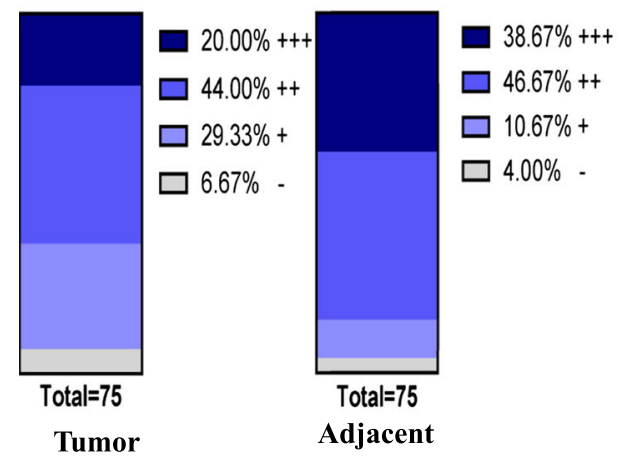

d

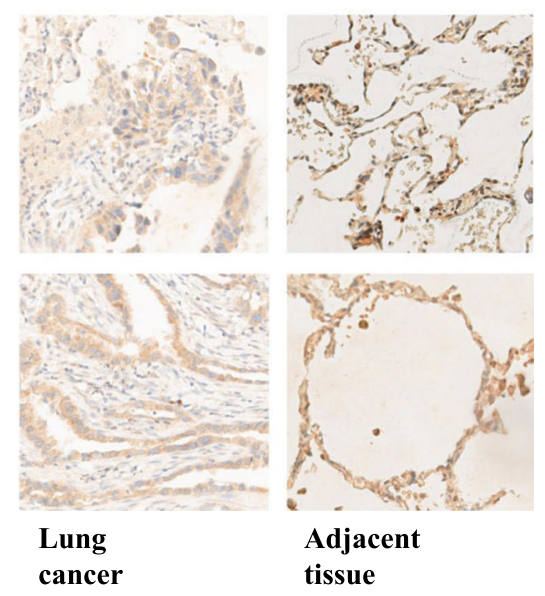

Fig. 1 The expression of NMI was down-regulated in lung cancer cells and tumor tissues. a Western blot and quantitative analysis of NMI protein expression in human normal lung fibroblasts cells (HLF), immortalized human epidermal cells (HBE) and lung cancer cells (H322, H1299, H460 and A549). $\mathbf{b}$ Western blot and quantitative analysis of the expression of NMI protein in human lung cancer tissues (T) and adjacent normal lung tissues (N). c The distribution of lung adenocarcinoma patients with various levels of NMl expression in tumor tissues and adjacent normal lung tissues $(n=75)$. d Representative images of NMI immunohistochemical (IHC) staining in human lung adenocarcinoma tissues and adjacent normal lung tissues (10x magnification)

$\beta$-cadherin was unaffected (Fig. 3c). In contrast, in the NMI-overexpressed cells, MMP9 and $\beta$-cadherin was down-regulated, whereas E-cadherin was upregulated (Fig. 3d). These results indicated that NMI played a vital role in the inhibition of cancer cell migration.

\section{NMI inhibited transcriptional activation of COX-2 and PGE2 production}

As NMI expression was inversely correlated with COX2 expression in lung adenocarcinoma (Fig. 1a, b), we tested if NMI regulated COX-2 transcription through interacting with its promoter in lung adenocarcinoma cells. We inserted the full-length promoter of COX-2 $(-891$ to +9$)$ as well as the truncated promoters COX-2 $(-459$ to +9$)$, COX-2 $(-362$ to +9$)$, COX-2 $(-193$ to $+9)$, COX-2 (-96 to +9$)$ and COX-2 $(-53$ to +9$)$ into the luciferase reporter vector (Fig. 4a). Luciferase activity assay showed that overexpression of NMI in A549 cells significantly repressed promoters COX-2 (-891 to +9) and COX-2 (-459 to +9) (Fig. 4b). We further confirmed that overexpression of NMI in A549 and H460 


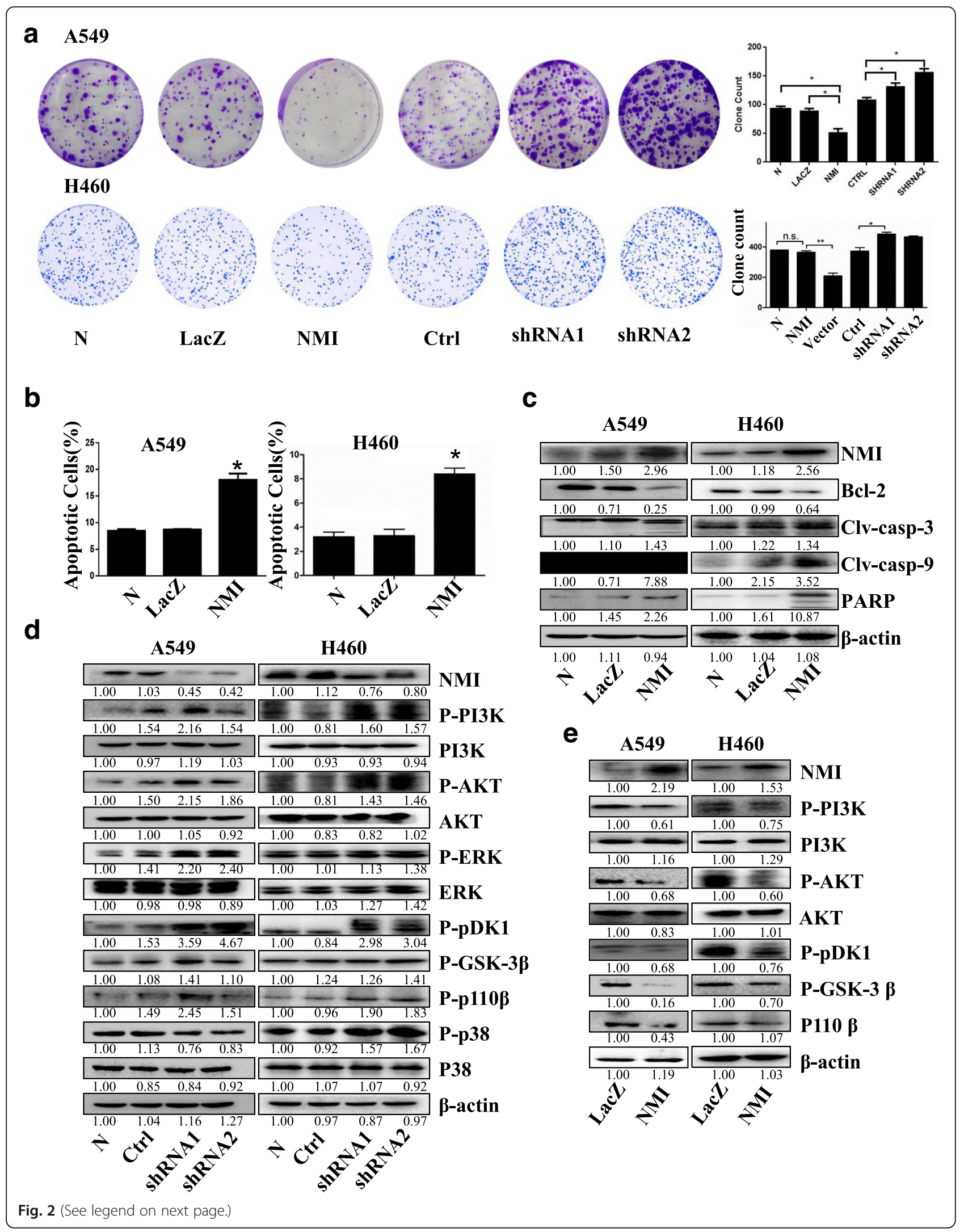


(See figure on previous page.)

Fig. 2 NMl inhibited clone formation and induced apoptosis in lung cancer cells. a Colony formation assay and quantitative analysis were performed with in A549 and H460 cells with NMI overexpression or knockdown. b FACS analysis was used to determine the relative percentage of apoptotic cells in A549 and $\mathrm{H} 460$ cells. c Western blot and quantitative analysis were used to detected the expression of Bcl-2, cleaved caspase-3/9 and phosphorylated PARP proteins in A549 and H460 cells at $48 \mathrm{~h}$ after transfection with NMI or control plasmids. $\mathbf{d}$ Western blot and quantitative analysis were used to detected the levels of phosphorylated PI3K, AKT, ERK, PKDK1, GSK-3ß, p110 3 and p38 proteins in A549 and $\mathrm{H} 460$ cells at $48 \mathrm{~h}$ after transfection with NMI-shRNAs or control. e Western blot and quantitative analysis were used to detected the

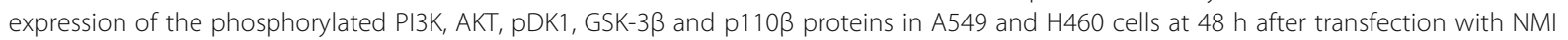
overexpression or control plasmids

cells caused decreased expression of COX-2 (Fig. 4c), while knockdown of NMI increased COX-2 expression in both A549 and H460 cells (Fig. 4d). In addition, overexpression of NMI in A549 and H1299 cells significantly reduced PGE2 production (Fig. 4e), which was consistent with inhibited COX-2 expression. Cell viability assay showed that overexpression of NMI caused significant cell death in A549 and H1299 cells (Fig. 4f), which might be a result of apoptosis induced by COX-2 inhibition [46-48].

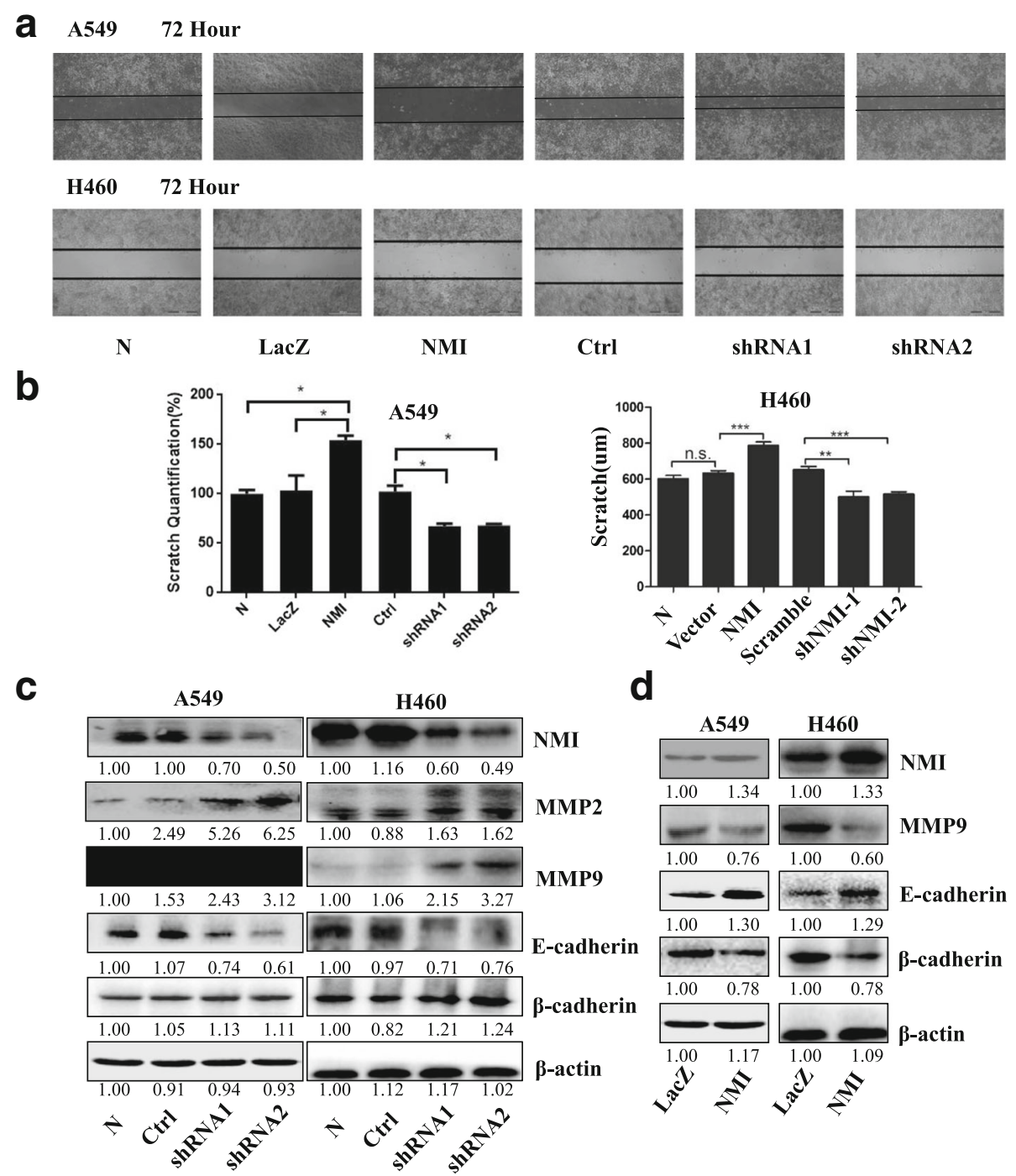

Fig. $3 \mathrm{NMl}$ inhibited lung cancer cell migration. a Scratch assay was used to detected the cell migration in A549 and H460 cells at $72 \mathrm{~h}$ after transfection with NMI overexpression/control plasmids or NMI shRNAs/control plasmids. b Quantification of scratch assay. c, d Western blot and quantitative analysis were used to detected the expression of MMP2, MMP9, E-cadherin and B-cadherin in A549 and H460 cells 


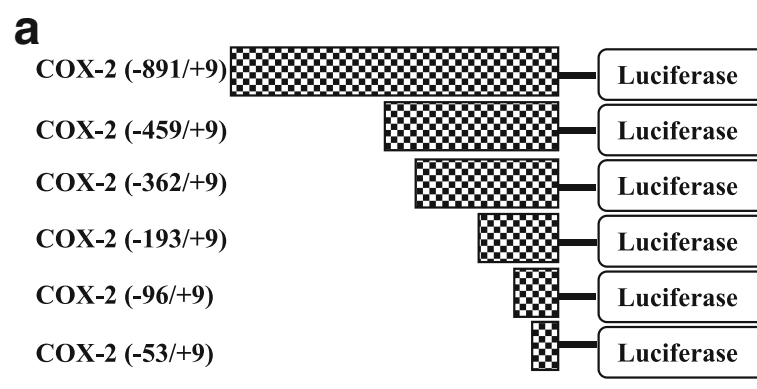

\section{C}

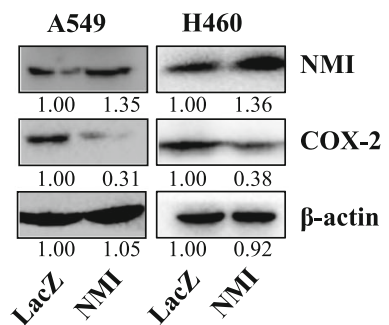

b

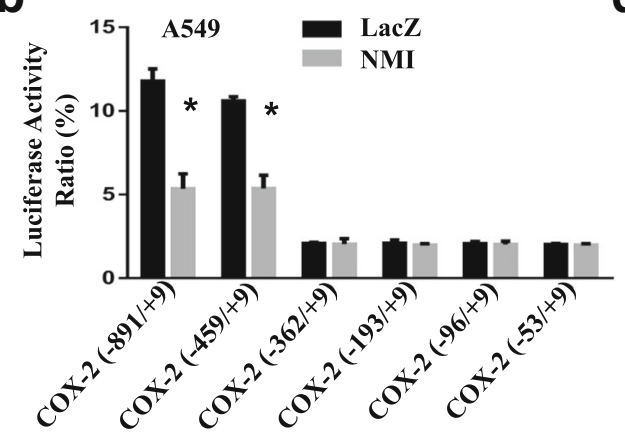

d

e

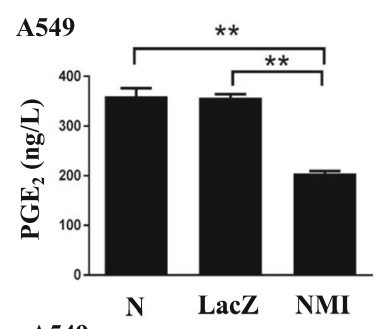

f

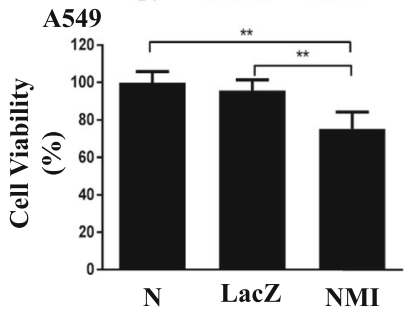

1549

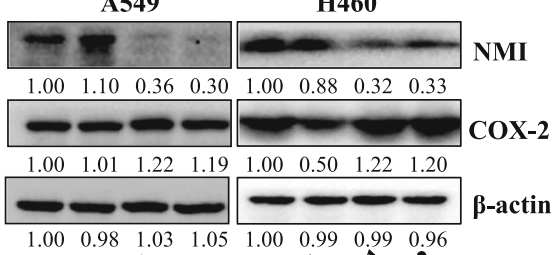

$\rightarrow c^{2}$
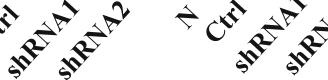

H1299

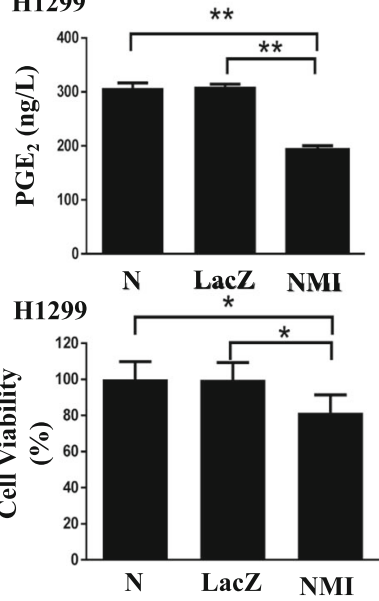

Fig. $4 \mathrm{NMI}$ regulated transcriptional activation of COX-2 and PGE2 production. a Schematic diagram of 6 different fragments of COX-2 promoter. b The activity of different fragments of COX-2 promoter was determined by luciferase reporter assay performed in A549 cells transfected with the control LacZ plasmid or the NMI overexpression plasmid. c $\mathbf{d}$ Western blot and quantitative analysis were used to detected the expression of COX-2 in A549 and H460 cells with NMl overexpression (C) or NMl knockdown (D). e The PGE 2 production level was measured in A549 and H1299 cell culture media at $72 \mathrm{~h}$ after transfection. f Cell viability was determined by MTT assay in A549 and H1299 cells

\section{NMI regulated COX-2 transcription through p300}

p300 is an important transcripional co-activator for COX-2 transcription and has been shown to acetylate COX-2 promoter-bound transactivators such as NF- $\mathrm{kB}$ to activate COX-2 expression [50]. To determine whether p300 plays a role in the NMI-mediated regulation of COX-2 transcription, we first examined the interaction between p300 and NMI. We queried the NCI-Cancer Genome Atlas (TCGA) data base for lung adenocarcinoma samples $(n=576)$, and found that the expression of NMI and p300 were inversely correlated, with Pearson correlation coefficient of -0.322 and $P<0.05$ (Fig. 5a, b). Immunofluorescence assay showed that the expression of p300 increased when NMI was knocked down (Fig. 5c). Next, we analyzed the subcellular localization of p300 and NMI in A549 and H1299 cells by immunofluorescence staining, and found that NMI and p300 co-localized in the cells (Fig. 5d). Furthermore, we observed in A549 cells that nuclear p300 was decreased when NMI was overexpressed, but was increased when NMI was knocked down (Fig. 5e, upper panel). Consistently, the acetylation level of p50 and p65 

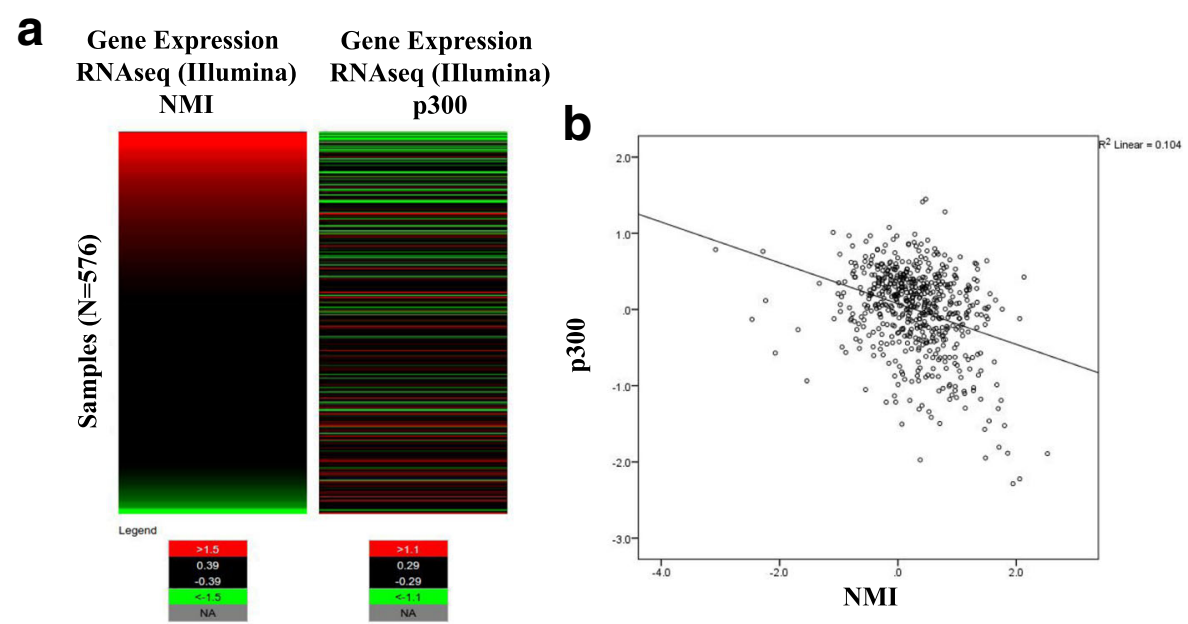

NMI \& p300 pearson $\mathrm{R}=-\mathbf{0 . 3 2 2 4 5 4}$
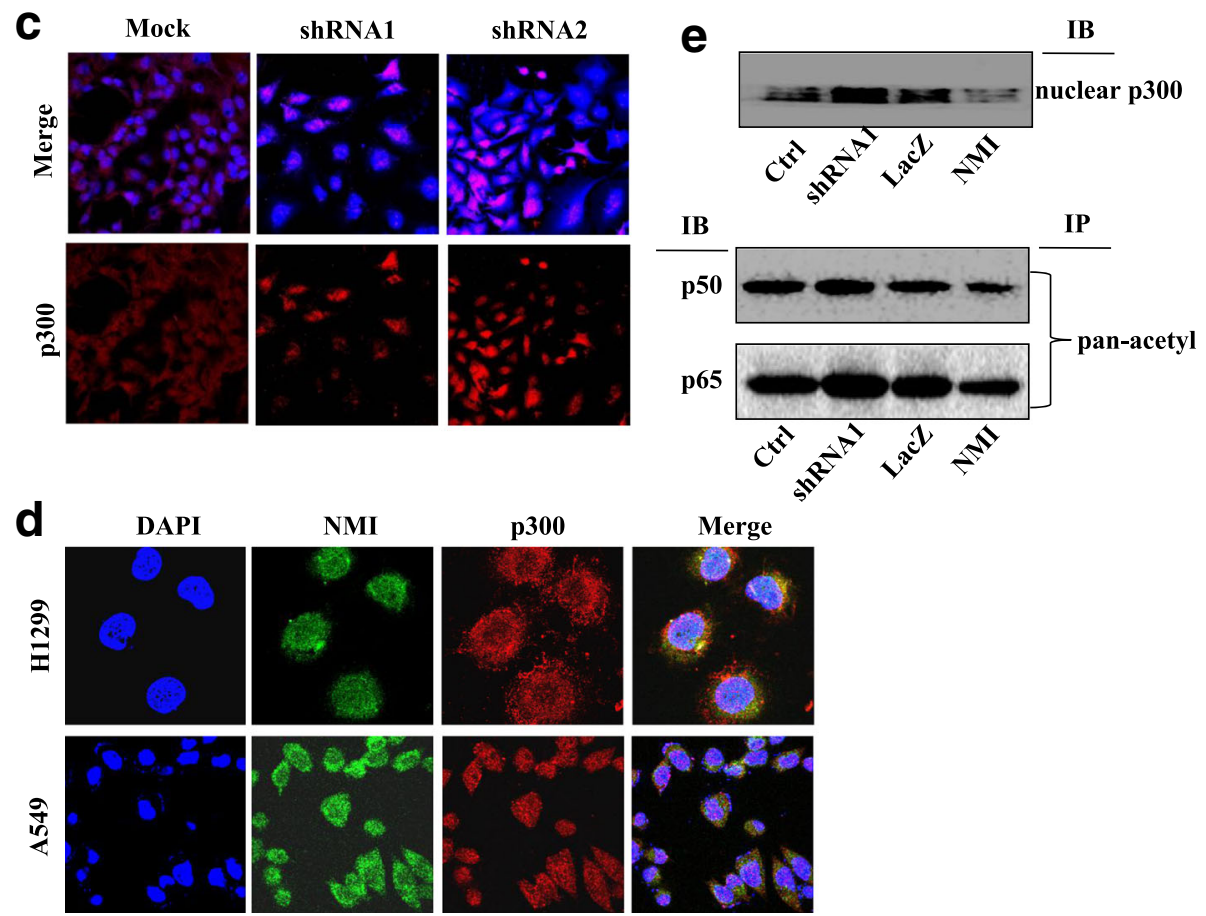

Fig. 5 NMI regulated COX-2 transcription through p300. a TCGA data was analyzed for the correlation of NMI and p300 gene expression levels $(n=576)$. Red $=$ high, black = medium, green = low. $\mathbf{b}$ Negative correlation in the expression of NMI and p300 was determined in TCGA database. c The expression of p300 in A549 cells with NMI knockdown was detected by immunofluorescence. $\mathbf{d}$ The subcellular localization of NMI and p300 in $\mathrm{H} 1299$ and A549 cells were examined by confocal microscopy. More than 100 cells were inspected per experiment, and cells with typical morphology were presented. e The expression of the nuclear p300 (upper panel), and the level of the nuclear p50 and p65 pulled down by the anti-pan-acetyl antibody (i.e. acetylated p50 and p65 in the nucleus, lower panel) were detected by western blot $48 \mathrm{~h}$ after transfection

NF- $\mathrm{kB}$, the nuclear targets of p300, was decreased in the NMI-overexpressed cells, but increased in the NMIknockdown cells (Fig. 5e, lower panel). These results indicated that NMI might repress COX-2 expression by inhibiting p300. To confirm these results, we overexpressed p300 together with NMI in lung cancer cell line A549. The results showed that overexpression of p300, but not its histone acetyl transferase (HAT) domain deletion mutant (DHAT), was able to rescue the decreases in cell viability caused by NMI overexpression (Fig. 6a). Consistently, p300 transfection in the NMIoverexpressed A549 cells also rescued the transcriptional inhibition of COX-2 promoter (Fig. 6b) and PGE2 production (Fig. 6c). 

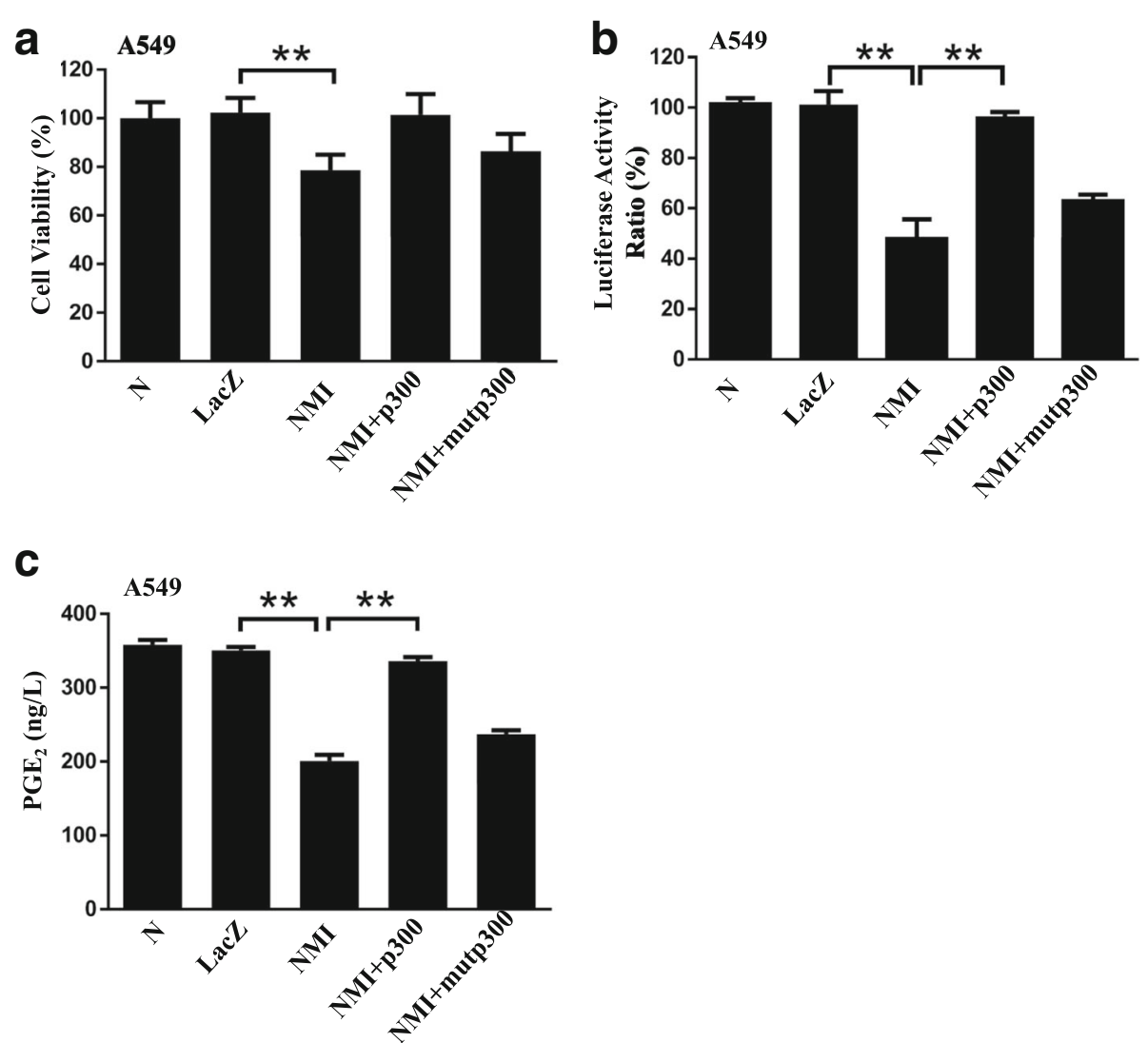

Fig. 6 Overexpression of p300 reversed the cellular effects caused by NMI overexpression. a Cell viability was measured by MTT assay in A549 cells transfected with LacZ control plasmid, NMI overexpression plasmid, NMI + p300 overexpression plasmids, or NMI + HAT domain-deleted p300 overexpression plasmids. b COX-2 promoter activity was determined by luciferase reporter assay in A549 cells transfected with NMI and p300 overexpression plasmids. c PGE 2 level was detected in the culture media of A549 cells transfected with NMI and p300 overexpression

\section{Overexpression of NMI suppressed tumor growth in a xenograft mouse model}

We validated the the suppression of NMI on lung cancer cell growth via the COX-2 in a xenograft mouse model. The A549 cells stably expressing NMI were injected into nude mice (flank) to establish human tumor xenograft. The results showed that overexpression of NMI significantly reduced tumor volume (Fig. $7 \mathrm{a}-\mathrm{e}$ ) and tumor weight (Fig. 7d). Lipopolysaccharide (LPS) is a COX-2 inducer and has been shown to be able to promote tumor growth. We found that LPS treatment could overcome the tumor growth inhibition caused by NMI overexpression (Fig. 7a-e). More importantly, knockdown of NMI combined with LPS treatment increased both the volume and weight of tumors, compared with the control group treated with LPS treatment alone (Fig. 7a-e). Moreover, immunohistochemical staining showed that NMI expression was negatively correlated with COX-2 expression in xenograft tumor tissues (Fig. 7f). These data further supported that NMI inhibited tumor cell growth through the suppression of COX-2 signaling in lung adenocarcinoma cells.
High NMI expression was correlated with low COX-2 expression and predicted favorable prognosis in NSCLC patients

We next evaluated the expression of NMI and COX-2 in tumor samples from 75 NSCLC patients by immunohistochemical (IHC) staining of tissue microarray. The expression of NMI and COX-2 in each IHC sample was classified either as high (score $>6$ ) or low (score $\leq 6$ ), using the median of the IHC scores as the cut-off value. We found that the expression of COX-2 was negatively correlated with NMI expression (Fig. 8a, b) (Pearson correlation coefficient $-0.427, P<0.001$ ).

Kaplan-Meier analyses of the overall survival revealed that the high NMI expression group (IHC staining with strong and moderate expression) had a better prognosis than the low NMI group (IHC staining with weak and negative expression) $(P<0.01)$ (Fig. 8c). In addition, we further assessed the correlation between NMI expression and lung adenocarcinoma patients' overall survival in a 720 lung adenocarcinoma patient cohort from the KMPLOT database (http://www.kmplot.com) by KaplanMeier analyses, and found that NMI high expression 

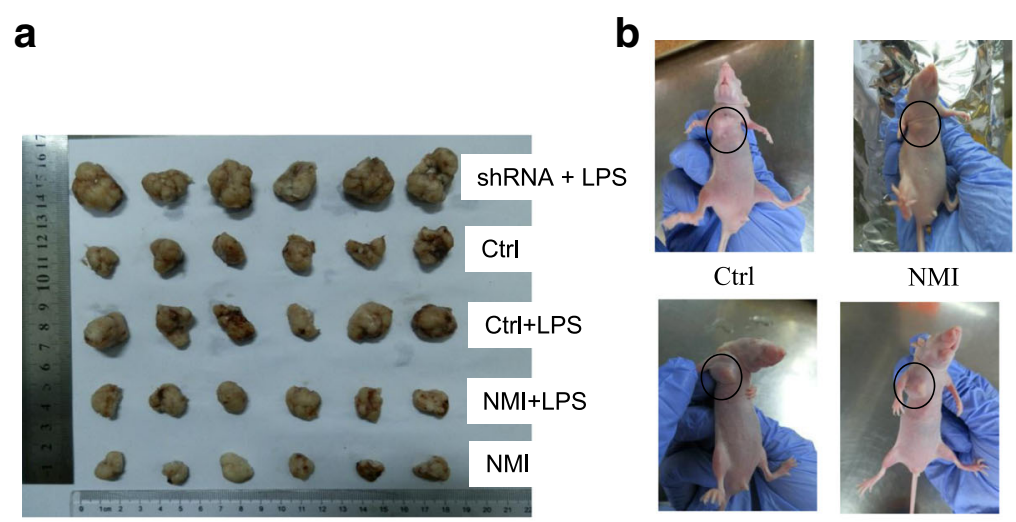

Ctrl

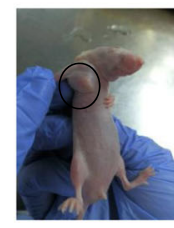

NMI
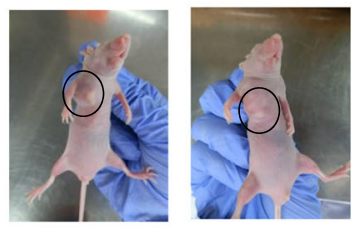

Ctrl + LPS

NMI+LPS $\quad$ shRNA +LPS
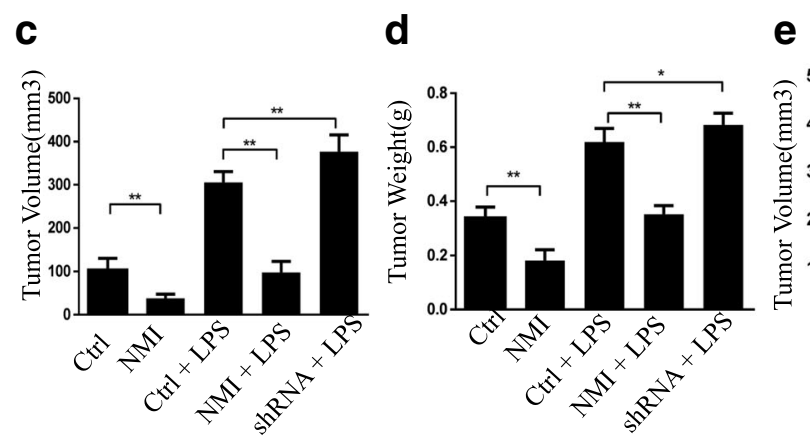

\section{e}
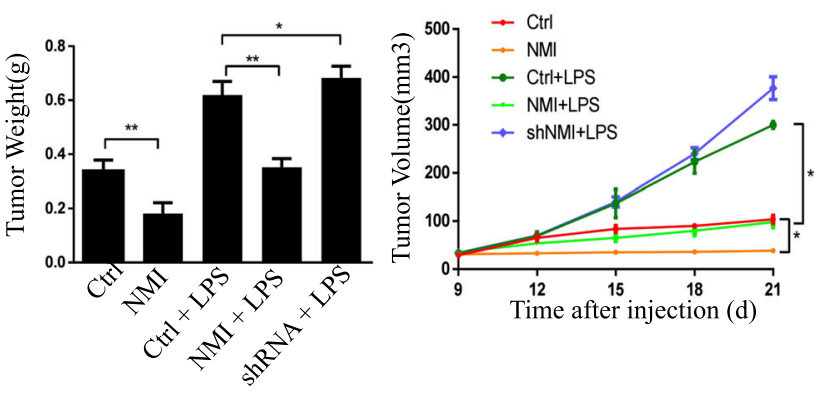

f

NMI

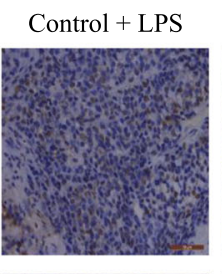

NMI+LPS

shNMI+LPS
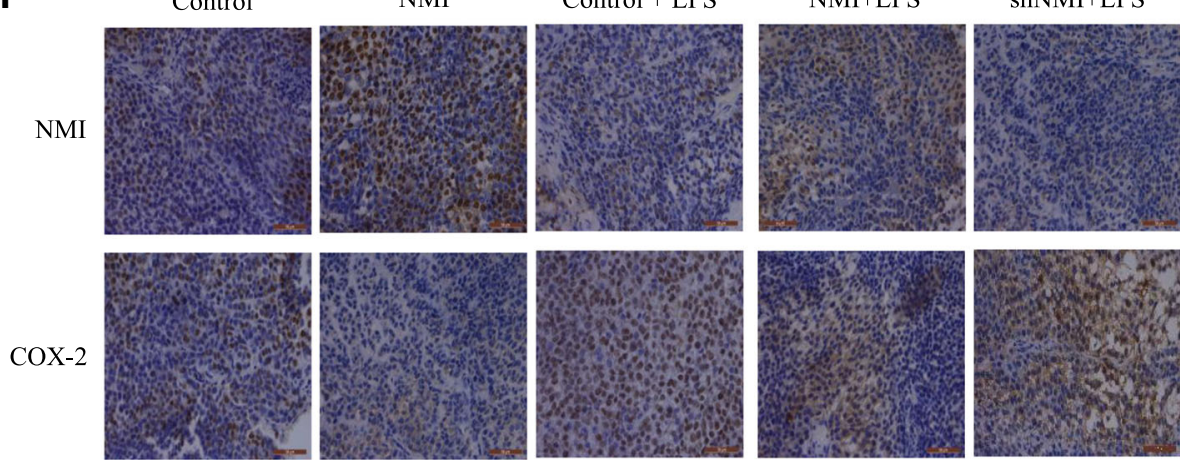

Fig. 7 Overexpression of NMI suppressed tumor growth in a xenograft mouse model. Human A549 cells transfected respectively with (1) control plasmid (Ctrl), (2) NMl overexpression plasmid (NMI), (3) Ctrl + LPS, (4) NMI + LPS, (5) NMI shRNA + LPS (shRNA + LPS) were injected into the right flank of nude mice ( $n=6$ per group). a Tumors from the mice after sacrifice. b Representative images of the xenograft-bearing mice. c Tumor volume of each mouse at the time of sacrifice was measured. $\mathbf{d}$ Tumor weight of each mouse at the end of the experiment was measured. e Tumor volume of each mouse was recorded every three days during the course of the experiment. $\mathbf{f}$ The expression of NMI and COX-2 in xenografts were detected by HE and immunohistochemical staining (400 × magnification)

patients had significantly longer overall survival (OS) than NMI low expression patients in the 720 lung adenocarcinoma patient (Fig. 8d).

For the 75 lung adenocarcinoma patients in our study, the correlation between NMI expression and clinicopathologic features was further evaluated and summarized in Table 1. The data showed no significant correlation between NMI downregulation and patient's gender $\left(P=0.351, \chi^{2}\right.$ tests), age ( $\geq 60$ vs. $<60$ years old $)$ $\left(P=0.816, \chi^{2}\right.$ tests $)$, T classification $\left(P=0.443, \chi^{2}\right.$ tests $)$ and $\mathrm{N}$ classification ( $P=0.451, \mathrm{x}^{2}$ tests). We next used a univariate analysis to evaluate associations between patient prognosis and several clinicopathologic factors including NMI expression (high vs. low), gender (male vs. female), age ( $\geq 60$ vs. $<60$ years old), $\mathrm{T}$ stage (T3-T4 vs.T1) and $\mathrm{N}$ stage $(\mathrm{N} 2+\mathrm{N} 3+\mathrm{Nx}$ vs. N0 + N1). The results showed that high NMI expression was significantly associated with inferior overall survival $(P=0.008$, $\mathrm{HR}=0.378$ ) (Table 2). Multivariate analysis also indicated that high NMI level was an independent prognostic factor for overall survival in patients with lung adenocarcinomas (Table 2). Taken together, all these 


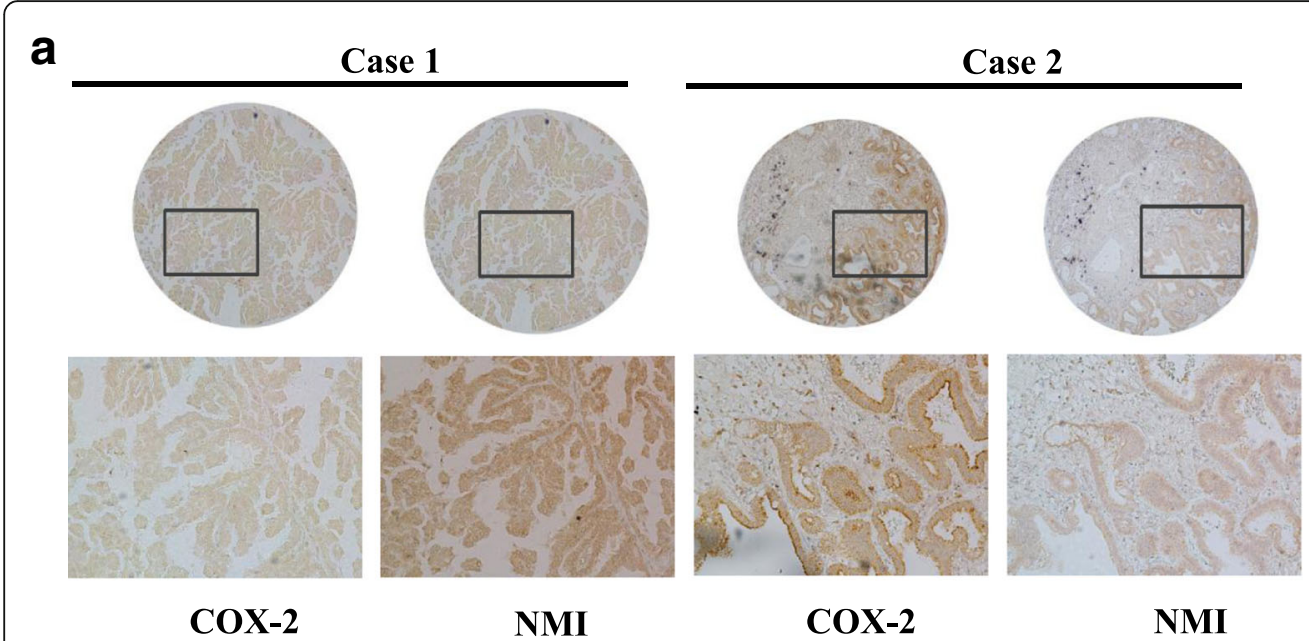

b Pearson Correlation $-\mathbf{0 . 4 2 7}, \boldsymbol{P}<\mathbf{0 . 0 0 1}$

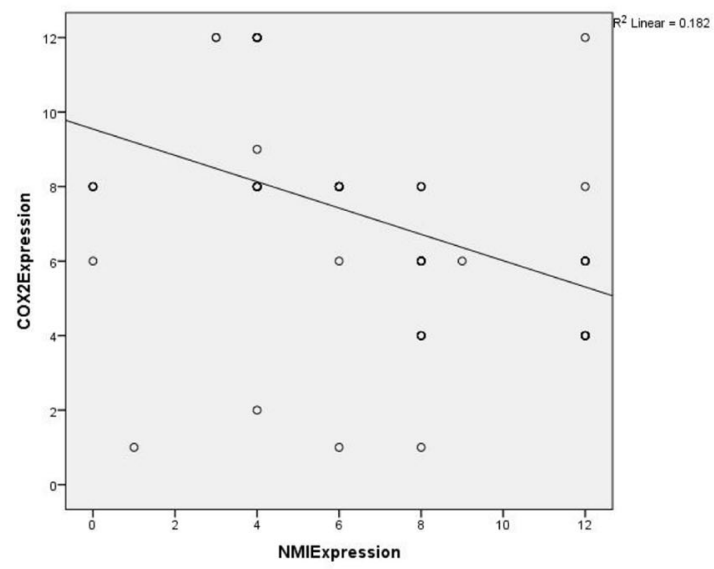

C

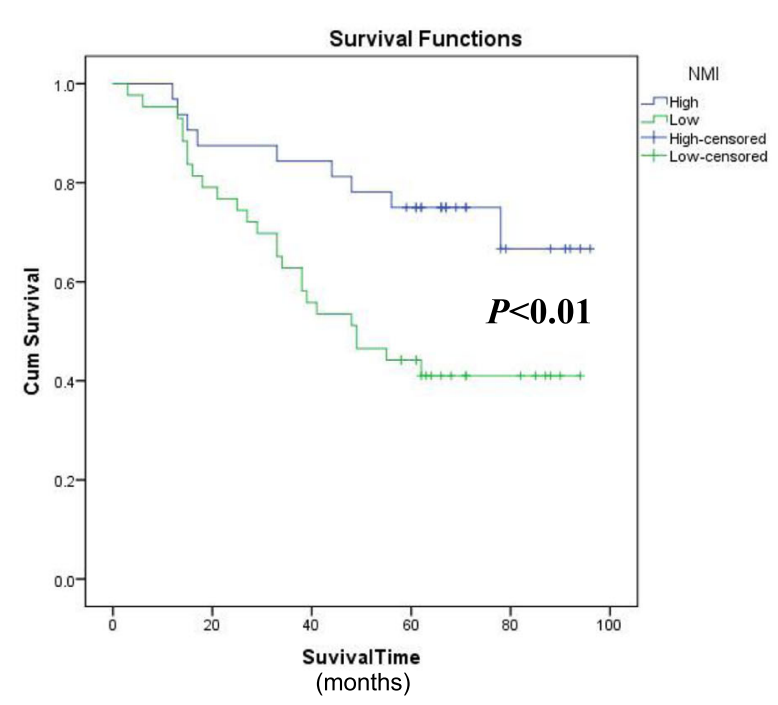

d

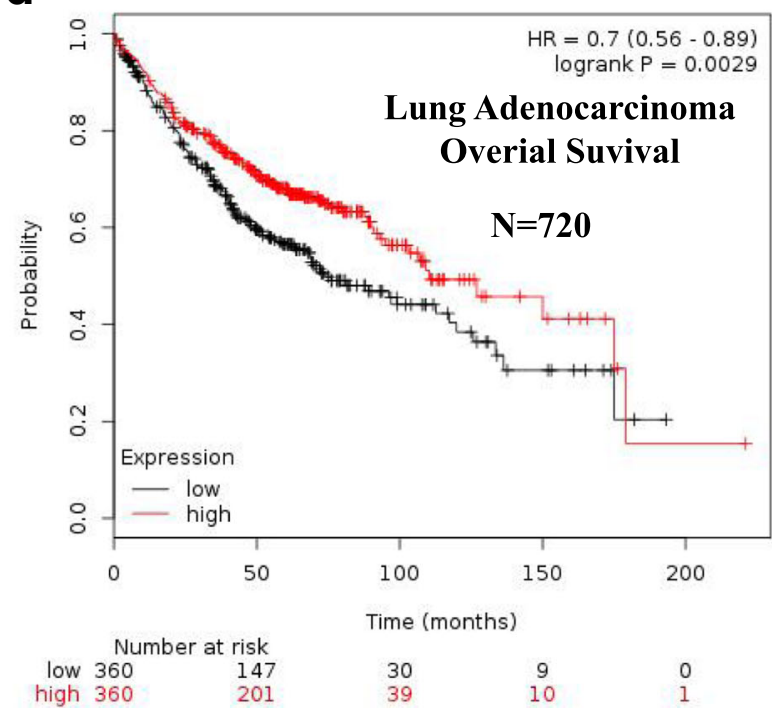

Fig. 8 (See legend on next page.) 
(See figure on previous page.)

Fig. 8 High NMI expression was correlated with low COX-2 expression and predicted favorable prognosis in NSCLC patients. a Representative images of the immunohistochemical staining of NMI and COX-2 in human lung adenocarcinoma tissues. $\mathbf{b} \mathrm{NMl}$ expression was negatively correlated with COX-2 expression in lung adenocarcinoma samples (Pearson's correlation test, $R=-0.427, P<0.001$ ). c Kaplan-Meier analysis of the overall survival of 75 lung adenocarcinoma patients with different NMI expression. $\mathbf{d}$ Kaplan-Meier analysis of the overall survival of 720 lung adenocarcinoma patients with different NMI expression in KM PLOTTER database

findings suggested that high expression of NMI indicated better prognosis of lung adenocarcinoma patients.

\section{Discussion}

The data presented here have demonstrated that NMI functions as a COX-2 regulator in human NSCLC cells. Up-regulated expression of COX-2 in various cancers [37] and loss of NMI expression in advanced breast cancer [15] have been documented independently. Our data suggest that NMI plays a crucial role in the regulation of COX-2 transactivation. Overexpression of NMI resulted in the decrease of COX-2 expression and PGE2 production. Conversely, knockdown of NMI promoted COX-2 expression and PGE2 production. Overexpression of NMI in lung adenocarcinoma cells also inhibited cell proliferation and migration. In addition, we found that NMI expression was lower in lung cancer tumor tissues compared to the adjacent normal tissues. More importantly, human tissue arrays revealed that overexpression of NMI indicated a better prognosis in lung adenocarcinoma patients. Consistent with our results, recent reports have also shown that NMI inhibited tumor development [18]. Devine et al. found that NMI protein expression is higher in early stage breast cancer than in later stages, with the lowest expression observed in patients with stage IV breast cancer. Moreover, NMI mRNA expression is inversely related to the grade of clinical breast cancer specimens, indicating that the loss of NMI correlates with progression to aggressive disease [15]. Thus, loss of NMI may be associated with the progression of cancer.

In our study, we found that there was a significant negative correlation (Pearson correlation coefficient -0.322 , $P=0.011$ ) between the expression of NMI and p300 in lung adenocarcinoma in TCGA database which contains 576 samples. In our own cohort containing 75 paired NSCLC normal and tumor samples, we also revealed a negative correlation between the expression of NMI and COX-2. More importantly, down-regulation of NMI was associated with poor survival of patients, which is further validated using the public database containing 720 patients. These data suggest NMI may function as a tumor suppressor in NSCLC. However, in this study, we used only a small volume of samples (75 totally). For the $\mathrm{T}$ stage, most of the patients (42 patients) were T2. Thus, we compared the survival between T3/T4 versus T1 groups. We could see a trend towards poorer survival for the late $\mathrm{T}$ stage group (the left figure). For the N stage, N0 and N1 samples were merged (52 totally) and compared to the rest of samples (23 totally). We could see a similar trend towards poorer survival in the late $\mathrm{N}$ stage group (the right figure). Unfortunately, the difference in both comparisons were in-significant. This may be caused by the small sample volumes, in the future study, we will increase sample sizes to solve the problem.

Table 1 Association of NMl expression with patients' clinicopathological features in human lung adenocarcinoma $(n=75)$

\begin{tabular}{|c|c|c|c|c|}
\hline & Total adenocarcinoma $(N=75)$ & NMI low expression $(N=43)$ & NMI high expression $(N=43)$ & $p$ \\
\hline \multicolumn{5}{|l|}{ Gender } \\
\hline Male & 39 & $20(51.3 \%)$ & $19(48.7 \%)$ & \multirow[t]{2}{*}{0.351} \\
\hline Female & 36 & $23(63.9 \%)$ & $13(36.1 \%)$ & \\
\hline \multicolumn{5}{|l|}{ Age at diagnosis } \\
\hline$<60$ & 43 & $24(55.8 \%)$ & 19 (44.2\%) & \multirow[t]{2}{*}{0.816} \\
\hline$\geq 60$ & 32 & 19 (59.4\%) & $13(40.6)$ & \\
\hline \multicolumn{5}{|l|}{ pT factor } \\
\hline $\mathrm{T} 1$ & 21 & $9(42.9 \%)$ & $12(57.1 \%)$ & \multirow[t]{3}{*}{0.443} \\
\hline $\mathrm{T} 2$ & 42 & $25(59.5 \%)$ & $17(40.5 \%)$ & \\
\hline $\mathrm{T} 3+\mathrm{T} 4$ & 12 & $6(50 \%)$ & $6(50 \%)$ & \\
\hline \multicolumn{5}{|l|}{ pN factor } \\
\hline $\mathrm{N} 0+\mathrm{N} 1$ & 52 & $28(53.8 \%)$ & $24(46.2 \%)$ & \multirow[t]{2}{*}{0.4513} \\
\hline $\mathrm{N} 2+\mathrm{N} 3+\mathrm{NX}$ & 23 & $15(65.2 \%)$ & $8(34.8 \%)$ & \\
\hline
\end{tabular}


Table 2 Cox proportional hazards model analysis of various prognostic factors in patients with lung adenocarcinoma

\begin{tabular}{|c|c|c|c|c|}
\hline & Hazard ratio & 95\% Confidence interval & Unfavorable/Favorable & $p$ \\
\hline \multicolumn{5}{|c|}{ Univariate analysis } \\
\hline NMI & 0.378 & $(0.176,0.813)$ & Low/High & 0.008 \\
\hline Gender & 1.069 & $(0.545,2.097)$ & Male/Female & 0.847 \\
\hline Age, y & 0.795392 & $(0.398,1.589)$ & $<60 y / \geq 60 y$ & 0.517 \\
\hline pT factor & 1.382 & $(0.835,2.289)$ & $\mathrm{T} 3+\mathrm{T} 4 / \mathrm{T} 1$ & 0.209 \\
\hline pN factor & 1.39 & $(0.687,2.813)$ & $\mathrm{N} 2+\mathrm{N} 3+\mathrm{NX} / \mathrm{NO}+\mathrm{N} 1$ & 0.359 \\
\hline \multicolumn{5}{|c|}{ Multivariate analysis } \\
\hline NMI & 0.370 & $(0.171,0.800)$ & Low/High & 0.011 \\
\hline pT factor & 1.441 & $(0.840,2.474)$ & $\mathrm{T} 3+\mathrm{T} 4 / \mathrm{T} 1$ & 0.185 \\
\hline pN factor & 1.391 & $(0.577,2.457)$ & $\mathrm{N} 2+\mathrm{N} 3+\mathrm{NX} / \mathrm{N} 0+\mathrm{N} 1$ & 0.637 \\
\hline
\end{tabular}

We also found that the survival curves of NMI high and low expression groups crossed at 170 months in a 720 lung adenocarcinoma patient cohort from the KMPLOT database This mabe be due to several outlier patients who live for quite long time, which is not usually seen for lung cancer. A plausible explanation may be that those patients are actually died of other causes. As a result, the two curves tend to overlap after long time followup. If looking at the earlier parts of the curves, such as five years or ten years, the two groups are actually widely separated.

In our current study, we didn't observe a perfect inverse correlation between NMI and COX-2 in our randomly selected 4 cell lines. Two cell lines H322 and H1299 showed low NMI expression but negative COX-2 expression. This may reflect the complex regulatory network of COX-2 in cancer cells. Actually, many other factors, such as IL- 1 and HIF1 $\alpha$, have been identified to regulate COX-2 expression. It's possible that these unknown factors may interfere with NMI/COX-2 signaling. However, in a much larger cohort of clinical samples, we observed a statistically significant inverse correlation between NMI and COX-2.

As a common transcriptional coactivator, p300 has been proved to be involved in the regulation of COX-2 gene expression. We therefore hypothesized that p300 interact with NMI, and they have opposite effect on the regulation of COX-2 expression. Our data supported the hypothesis that overexpression of NMI reduced nuclear p300 localization and the acetylation of its targets p50 and p65 NF-kB. Moreover, the elevated p300 level could rescue the inhibition of COX-2 expression and cell proliferation in NMI overexpressed cells. These data indicate p300 may play an important role in the NMImediated regulation of COX-2 expression in lung adenocarcinoma cells. Further studies are needed to confirm the detailed molecular mechanisms by which NMI regulates COX-2 expression.

\section{Conclusions}

In summary, we have discovered that NMI plays an important role in the regulation of COX-2 expression and tumor growth in lung adenocarcinoma, and high expression of NMI suggests to a better prognosis in human adenocarcinoma. Our study therefore suggests that the $\mathrm{NMI} / \mathrm{COX}-2$ signaling pathway is a potential prognostic biomarker for lung cancers.

\section{Abbreviations}

AC: Oadenocarcinoma; EGFR: Epidermal growth factor receptor; EML 4ALK: Echinoderm microtubule-associated protein-like 4-anaplastic lymphoma kinase; EMT: Epithelial-mesenchymal-transition; HAT: Histone acetyltransferase; NMI: (N-myc (and STAT) interactor; NSCLC: Non-small-cell lung cancer; PGE2: Prostaglandin E2

\section{Acknowledgements}

Not applicable.

\section{Funding}

This work was supported by the funds from the National Natural Science Foundation of China $(81472178,81401905,81322029,31371512)$, the Natural Science Foundation of Guangdong Province (2016A03031100; 2015A030313018), the Guangdong Esophageal Cancer Institute (2015A09), and the State "973 Program" of China (2014CB542005).

\section{Availability of data and materials}

All data generated or analyzed during this study are included in this published article [and its Additional files].

\section{Authors' contributions}

The authors (JW, KZ and XF) contributed equally to this work. The work was carried out in collaboration among all authors. JW, XY, XW and WD defined the research theme, designed the experimental approach, and revised the manuscript critically. JW, KZ, XF, MC, CL, RT, YX, HQ, GQ, YL, CZ, BX, JP and LK designed methods and experiments and carried out most of the experiments. WC, ML, WH, XF and WD analyzed the data and interpreted the results. JW, MC, XW and WD wrote the manuscript. All authors read and approved the final manuscript.

Ethics approval and consent to participate

This study was reviewed and approved by the Ethics Committee of Sun Yat-sen University Cancer Center.

Consent for publication Not applicable. 


\section{Competing interests}

The authors declare that they have no competing interests.

\section{Publisher's Note}

Springer Nature remains neutral with regard to jurisdictional claims in published maps and institutional affiliations.

\section{Author details}

'Sun Yat-sen University Cancer Center; State Key Laboratory of Oncology in South China; Collaborative Innovation Center of Cancer Medicine, Guangzhou, China. ${ }^{2}$ Shunde Hospital, Southern Medical University, Foshan, China. ${ }^{3}$ The First Affiliated Hospital of Dalian Medical University, Dalian, China. ${ }^{4}$ Institute of Cancer Stem Cell, Dalian Medical University, Dalian, China. ${ }^{5}$ Sun Yat-Sen Memorial Hospital of Sun Yat-Sen University, Guangzhou, China. ${ }^{6}$ Cancer Center, Union Hospital, Tongji Medical College, Huazhong University of Science and Technology, Wuhan, China. ${ }^{7}$ State Key Laboratory of Targeted Drug for Tumors of Guangdong Province, Guangzhou Double Bioproduct Inc., Guangzhou, China.

\section{Received: 18 January 2017 Accepted: 12 July 2017}

\section{Published online: 12 October 2017}

\section{References}

1. Torre LA, et al. Global cancer statistics, 2012. CA Cancer J Clin. 2015;65(2):87-108

2. Siegel RL, Miller KD, Jemal A. Cancer statistics, 2015. CA Cancer J Clin. 2015;65(1):5-29.

3. Chen W, et al. Cancer statistics in China, 2015. CA Cancer J Clin. 2016:66(2):115-32

4. Chen Z, et al. Non-small-cell lung cancers: a heterogeneous set of diseases. Nat Rev Cancer. 2014;14(8):535-46.

5. Warth A, et al. The novel histologic International Association for the Study of Lung Cancer/American Thoracic Society/European Respiratory Society classification system of lung adenocarcinoma is a stage-independent predictor of survival. J Clin Oncol. 2012;30(13):1438-46.

6. Kwak EL, et al. Anaplastic lymphoma kinase inhibition in non-small-cell lung cancer. N Engl J Med. 2010;363(18):1693-703.

7. Pao W, Chmielecki J. Rational, biologically based treatment of EGFR-mutant non-small-cell lung cancer. Nat Rev Cancer. 2010;10(11):760-74.

8. Reck $M$, et al. Management of non-small-cell lung cancer: recent developments. Lancet. 2013:382(9893):709-19.

9. Zhu M, et al. Functional association of Nmi with Stat5 and Stat1 in IL-2- and IFNgamma-mediated signaling. Cell. 1999;96(1):121-30.

10. Bannasch D, Weis I, Schwab M. Nmi protein interacts with regions that differ between MycN and Myc and is localized in the cytoplasm of neuroblastoma cells in contrast to nuclear MycN. Oncogene. 1999;18(48):6810-7.

11. Bao J, Zervos AS. Isolation and characterization of Nmi, a novel partner of Myc proteins. Oncogene. 1996;12(10):2171-6.

12. Chen J, et al. Interferon-inducible Myc/STAT-interacting protein Nmi associates with IFP 35 into a high molecular mass complex and inhibits proteasomemediated degradation of IFP 35. J Biol Chem. 2000;275(46):36278-84.

13. Schlierf $B$, et al. The high-mobility group transcription factor Sox10 interacts with the N-myc-interacting protein Nmi. J Mol Biol. 2005;353(5):1033-42.

14. Zhang K, Zheng G, Yang YC. Stability of Nmi protein is controlled by its association with Tip60. Mol Cell Biochem. 2007;303(1-2):1-8.

15. Devine DJ, et al. Loss of N-Myc interactor promotes epithelial-mesenchymal transition by activation of TGF-beta/SMAD signaling. Oncogene. 2014:33(20):2620-8.

16. Rostas JR, et al. microRNA-29 negatively regulates EMT regulator $\mathrm{N}$-myc interactor in breast cancer. Mol Cancer. 2014;13:200.

17. Samant RS, Shevde LA. NMI and EMT. Oncoscience. 2014;1(7):476-7.

18. Fillmore RA, et al. Nmi (N-Myc interactor) inhibits Wnt/beta-catenin signaling and retards tumor growth. Int J Cancer. 2009;125(3):556-64

19. Metge BJ, et al. N-Myc and STAT Interactor regulates autophagy and chemosensitivity in breast cancer cells. Sci Rep. 2015:5:11995.

20. Sun GJ, et al. Identification of a protein interacting with apoptin from human leucocyte cDNA library by using yeast two-hybrid screening. Sheng Wu Hua Xue Yu Sheng Wu Wu Li Xue Bao (Shanghai). 2002;34(3):369-72.

21. Nagel $\mathrm{S}$, et al. Transcriptional deregulation of oncogenic myocyte enhancer facto 2C in T-cell acute lymphoblastic leukemia. Leuk Lymphoma. 2011;52(2):290-7.

22. Ghosh N, et al. COX-2 as a target for cancer chemotherapy. Pharmacol Rep. 2010;62(2):233-44
23. Cha YI, DuBois RN. NSAIDs and cancer prevention: targets downstream of COX-2. Annu Rev Med. 2007:58:239-52.

24. Chan AT, Ogino S, Fuchs CS. Aspirin and the risk of colorectal cancer in relation to the expression of COX-2. N Engl J Med. 2007;356(21):2131-42.

25. Tomozawa S, et al. Cyclooxygenase-2 overexpression correlates with tumour recurrence, especially haematogenous metastasis, of colorectal cancer. $\mathrm{Br}$ ] Cancer. 2000;83(3):324-8.

26. Kim HS, et al. COX2 overexpression is a prognostic marker for Stage III breast cancer. Breast Cancer Res Treat. 2012;132(1):51-9.

27. Khuri FR, et al. Cyclooxygenase-2 overexpression is a marker of poor prognosis in stage I non-small cell lung cancer. Clin Cancer Res. 2001;7(4):861-7.

28. Hida T, et al. Increased expression of cyclooxygenase 2 occurs frequently in human lung cancers, specifically in adenocarcinomas. Cancer Res. 1998; 58(17):3761-4.

29. Shirahama T, Sakakura C. Overexpression of cyclooxygenase-2 in squamous cell carcinoma of the urinary bladder. Clin Cancer Res. 2001;7(3):558-61.

30. Bostrom PJ, et al. Expression of cyclooxygenase-1 and -2 in urinary bladder carcinomas in vivo and in vitro and prostaglandin E2 synthesis in cultured bladder cancer cells. Pathology. 2001:33(4):469-74.

31. Mohammed SI, et al. Expression of cyclooxygenase-2 (COX-2) in human invasive transitional cell carcinoma (TCC) of the urinary bladder. Cancer Res. 1999;59(22):5647-50

32. Kim YB, et al. Overexpression of cyclooxygenase-2 is associated with a poor prognosis in patients with squamous cell carcinoma of the uterine cervix treated with radiation and concurrent chemotherapy. Cancer. 2002;95(3):531-9.

33. Kulkarni $\mathrm{S}$, et al. Cyclooxygenase-2 is overexpressed in human cervical cancer. Clin Cancer Res. 2001:7(2):429-34.

34. Shiota $\mathrm{G}$, et al. Cyclooxygenase-2 expression in hepatocellular carcinoma. Hepato-Gastroenterology. 1999:46(25):407-12.

35. Okami J, et al. Overexpression of cyclooxygenase-2 in carcinoma of the pancreas. Clin Cancer Res. 1999:5(8):2018-24.

36. Yip-Schneider MT, et al. Cyclooxygenase-2 expression in human pancreatic adenocarcinomas. Carcinogenesis. 2000;21(2):139-46.

37. Gupta $\mathrm{S}$, et al. Over-expression of cyclooxygenase-2 in human prostate adenocarcinoma. Prostate. 2000:42(1):73-8.

38. Higashi $Y$, Kanekura T, Kanzaki T. Enhanced expression of cyclooxygenase (COX)-2 in human skin epidermal cancer cells: evidence for growth suppression by inhibiting COX-2 expression. Int J Cancer. 2000;86(5):667-71.

39. Wilson KT, et al. Increased expression of inducible nitric oxide synthase and cyclooxygenase-2 in Barrett's esophagus and associated adenocarcinomas. Cancer Res. 1998;58(14):2929-34.

40. Ratnasinghe $D$, et al. Expression of cyclooxygenase-2 in human squamous cell carcinoma of the esophagus; an immunohistochemical survey. Anticancer Res. 1999:19(1A):171-4.

41. Murata $\mathrm{H}$, et al. Cyclooxygenase-2 overexpression enhances lymphatic invasion and metastasis in human gastric carcinoma. Am J Gastroenterol. 1999:94(2):451-5.

42. Lim HY, et al. Increased expression of cyclooxygenase-2 protein in human gastric carcinoma. Clin Cancer Res. 2000;6(2):519-25.

43. McDade TP, et al. Salicylates inhibit NF-kappaB activation and enhance TNFalpha-induced apoptosis in human pancreatic cancer cells. J Surg Res. 1999; 83(1):56-61

44. Farrow DC, et al. Use of aspirin and other nonsteroidal anti-inflammatory drugs and risk of esophageal and gastric cancer. Cancer Epidemiol Biomark Prev. 1998;7(2):97-102

45. Krysan K, et al. COX-2-dependent stabilization of survivin in non-small cell lung cancer. FASEB J. 2004;18(1):206-8.

46. Suh $Y$, et al. A plant flavonoid fisetin induces apoptosis in colon cancer cells by inhibition of COX2 and Wnt/EGFR/NF-kappaB-signaling pathways. Carcinogenesis. 2009;30(2):300-7.

47. Kern MA, et al. Cyclooxygenase-2 inhibition induces apoptosis signaling via death receptors and mitochondria in hepatocellular carcinoma. Cancer Res. 2006;66(14):7059-66

48. Liu XH, et al. NS398, a selective cyclooxygenase-2 inhibitor, induces apoptosis and down-regulates bcl-2 expression in LNCaP cells. Cancer Res. 1998:58(19):4245-9.

49. Narumiya S, FitzGerald GA. Genetic and pharmacological analysis of prostanoid receptor function. J Clin Invest. 2001;108(1):25-30.

50. Deng WG, Zhu Y, Wu KK. Up-regulation of p300 binding and p50 acetylation in tumor necrosis factor-alpha-induced cyclooxygenase-2 promoter activation. J Biol Chem. 2003;278(7):4770-7. 
51. Deng WG, Zhu Y, Wu KK. Role of p300 and PCAF in regulating cyclooxygenase2 promoter activation by inflammatory mediators. Blood. 2004;103(6):2135-42.

52. Subbaramaiah K, Cole PA, Dannenberg AJ. Retinoids and carnosol suppress cyclooxygenase-2 transcription by CREB-binding protein/p300-dependent and -independent mechanisms. Cancer Res. 2002;62(9):2522-30.

53. Xiao $X$, et al. Quercetin suppresses cyclooxygenase-2 expression and angiogenesis through inactivation of P300 signaling. PLoS One. 2011; 6(8):e22934.

Submit your next manuscript to BioMed Central and we will help you at every step:

- We accept pre-submission inquiries

- Our selector tool helps you to find the most relevant journal

- We provide round the clock customer support

- Convenient online submission

- Thorough peer review

- Inclusion in PubMed and all major indexing services

- Maximum visibility for your research

Submit your manuscript at www.biomedcentral.com/submit 